\title{
Article
}

\section{The wider context of performance analysis and it application in the football coaching process}

Wright, C., Carling, C., and Collins, D.

Available at http://clok.uclan.ac.uk/12239/

Wright, C., Carling, C., ORCID: 0000-0002-7456-3493 and Collins, D. ORCID: 0000-0002-7601-0454 (2014) The wider context of performance analysis and it application in the football coaching process. International Journal of

Performance Analysis in Sport, 14 (3). pp. 709-733. ISSN 1474-8185

It is advisable to refer to the publisher's version if you intend to cite from the work.

For more information about UCLan's research in this area go to http://www.uclan.ac.uk/researchgroups/ and search for < name of research Group>.

For information about Research generally at UCLan please go to http://www.uclan.ac.uk/research/

All outputs in CLoK are protected by Intellectual Property Rights law, including Copyright law. Copyright, IPR and Moral Rights for the works on this site are retained by the individual authors and/or other copyright owners. Terms and conditions for use of this material are defined in the policies page.

\section{CLoK}

Central Lancashire online Knowledge www.clok.uclan.ac.uk

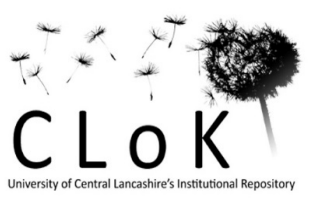


Running Title: The wider context of performance analysis and it application in the football coaching process.

This is an Accepted Manuscript of an article published by University of Wales, Cardiff, in International Journal of Performance Analysis in Sport on $1^{\text {st }}$ December 2014, available online: http://www.ingentaconnect.com/content/uwic/ujpa/2014/00000014/00000003/art00006

\section{PLEASE REFER TO THE PUBLISHED VERSION FOR CITING PURPOSES}

The wider context of performance analysis and it application in the football coaching process

Craig Wright ${ }^{1}$, Chris Carling ${ }^{2,3}$ David Collins ${ }^{2}$

Institutions:

${ }^{1}$ School of Sports Tourism and the Outdoors, University of Central Lancashire, UK ${ }^{2}$ Institute of Coaching and Performance, University of Central Lancashire, UK ${ }^{3}$ LOSC Lille Métropole Football Club, Domain de Luchin, Camphin-en-Pévèle, 59780, France 
Running Title: The wider context of performance analysis and it application in the football coaching process.

\begin{abstract}
The evolving role of PA and the associated proliferation of positions and internships within high performance sport has driven consideration for a change, or at least a broadening, of emphasis for use of PA analysis. In order to explore the evolution of PA from both an academic and practitioner perspective this paper considers the wider conceptual use of PA analysis. In establishing this, the paper has 4 key aims: (1) To establish working definitions of PA and where it sits within the contemporary sports science and coaching process continuum; (2) To consider how PA is currently used in relation to data generation; (3) To explore how PA could be used to ensure transfer of information, and; (4) To give consideration to the practical constrains potentially faced by coach and analyst when implementing PA strategies in the future.
\end{abstract}

Key Words: Coaches; Match analysis; Performance Analysts, Football. 
Running Title: The wider context of performance analysis and it application in the football coaching process.

\section{Introduction}

Within the academic literature, Performance Analysis (hereafter PA) research has largely focused around forms of notational analysis. Such work has attempted to quantify a multitude of game behaviours, generating number-based matrixes of performance, often in an attempt to tease out causal relationships; for example, the pattern of play which most often precedes a goal (Hughes \& Franks, 2005; Jones, James \& Mellalieu 2004, Bate, 1988, Stanhope, 2001). More recently, however, the evolving role of PA and the associated proliferation of positions and internships within high performance sport has driven consideration for a change, or at least a broadening of emphasis (Hatton 2013, O'Donoghue 2013, Edgar 2013a, Jones, 2013). There is an emergence of sources which have started to elude to the wider context in which PA tools and analysts operate, alongside and in (hopeful) collaboration with the coaching process (Groom, Cushion \& Nelson, 2011). As a result, consideration as to how data might start to translate into behaviour change in coach, player and practice behaviours is increasingly appropriate. For example, a number of recent presentations (Bourne, 2012; Kuper, 2012) have demonstrated how PA techniques can be used to address specific, performance-generated questions and then employed to drive and monitor genuine behaviour change. Unfortunately, however, while there is anecdotal evidence of these positive changes, the comparative absence of peer reviewed papers and more general employment of behaviour-focused PA suggest that this is an area which would benefit from further academic and practitioner inquiry.

Reflecting these contentions, in order to further explore these aspects and to develop evidencebased guidelines for optimum practice, a deeper understanding of PA and the analyst's role is still required. For example, it would appear that there is limited consensus or evidence on what constitutes more or less effective use of PA in this and other emerging applications (Wight, Atkins, Jones 2012; Wright, Atkins, Jones, Todd, 2013). Consequently, and in order to further illuminate the broader potential for PA, this paper will address the following key themes by employing an exemplar review approach to elucidate the points made and working through the medium of football as the most common user of PA.

1. Establish working definitions of PA and where it sits within the contemporary sports science and coaching process continuum.

2. How PA is currently used: Focus on quantitative analysis of technical and tactical parameters.

3. How PA could be used: The significance of wider contextual information.

4. The growing constraints that PA faces 
Running Title: The wider context of performance analysis and it application in the football coaching process.

\section{PA and where it sits within the contemporary sports science and coaching process continuum.}

The ethos of PA involves creating a valid record of performance by means of systematic observation that can be analysed in the attempt to promote change (Bishop, 2003). The early applications of PA analysis in football have tended to focus around the use of match and motion analysis techniques used by sports scientists to provide an evaluation of performance (Carling, Williams \& Reilly, 2007). More recently, PA has further evolved resulting in specialised performance analysts whose role has required them, in specific contexts, to become an integral part of the preparation and feedback of information to the coaching team and players (O'Donoghue 2010). This has largely revolved around the facilitation and dissemination of video compilations and game statistics. Despite the importance of such roles within some football clubs, however, it is not uncommon for performance analysts to have no or limited interaction with players, especially in football clubs on the continent (Carling, Wells, \& Lawlor, in press). Despite these most recent developments, the term performance analyst is a broad one and overlaps with facets of several other sport science disciplines. The most usual are biomechanics and notational analysis, but applied sports physiology and psychology have also employed notational, match or time motion analysis techniques to provide an evaluation and better understanding of performance, thus raising the question is notational analysis a legitimate 'stand alone' sports science discipline or just another tool available to the contemporary sports scientist. One of the most eminent and current researchers in this field has suggested that performance analysis is an area of sports and exercise science concerned with actual sports performance rather than self-reports by athletes or laboratory experiments (O'Donoghue 2010). Unlike these other data sources, PA is often associated with live assessment of performance in an un-contrived state, thus affirming its role in an applied setting. The actual assessment of performance brings with it many strengths and challenges. The most obvious strength being the potential level of ecological validity, in that the conditions investigated reflect the real world setting (O'Donoghue 2010). Challenges include lack of control over extraneous variables which one would hope to minimise in a laboratory setting. Some of these challenges will be discussed in the latter section, within the context of data collection and variability of data.

In light of these descriptions of performance analysis, especially in an applied context as outlined by O'Donoghue (2010), there clearly seems to be contention when considering the earlier definition of performance analysis. For example, the definitions proposed by Hughes and Bartlett (2002), who at the time suggested that the two disciplines of biomechanics and notational analysis should grow closer together. This was typified by Bartlett (2001) who identified that notation was central in identifying skills requiring attention by establishing simple positive to negative ratios. This 
Running Title: The wider context of performance analysis and it application in the football coaching process.

information would then be used to direct more detailed technique analysis, thus optimising the investment of time into areas that most required additional biomechanical analysis (Bartlett 2001). Thus an integration of notational analysis and biomechanics would seem appropriate. However at the time Bartlett (2001) also established a number of challenges requiring attention in the future thereby enabling 'a real fusion of the two disciplines' (Bartlett 2001:5) Although both biomechanics and notational analysis share some commonalities as described by both Bartlett (2001) and Glazier (2010), criticism has emerged from some quarters describing such a joining as a 'marriage of convenience' (Glazier 2010:1). Contention appears to be caused by a perceived 'dumbing down' (Glazier 2010:1) of biomechanical principles while physiologists and psychologists might also perceive themselves as performance analysts in their own right. The authors of this paper strongly argue against what has been described as the 'dumbing down' and support the wider applications of notational analysis, match analysis and time motion analysis techniques by a range of different sports scientists and performance coaches in many applied settings. This in turn has brought new knowledge and challenges. When we consider such definitions we might find that practitioners within a football setting more closely align themselves as either match analysts or video analysts to describe their roles and the predominant techniques they utilise as opposed to a clear definition of where they might sit within the sports science discipline (Carling et al in press). Possibly this might be as a result of the limited use in football of what we would describe as biomechanical techniques and processes outside the academic setting.

Within a professional football setting, match analysis appears to be one of the most common terms with regards to the use of video technology to enhance feedback, as opposed to PA (Carling, 2012). This might be qualified in terms of the contemporary job role of match analysts which largely requires them to produce and present 'key' breakdown statistics supported with complementary video compilations of critical game actions and sequences of play (Carling, Wright, Nelson, \& Bradley, 2013). If match analysts are required to engage with technical assessments of performance, these would most commonly be via live and off-line qualitative / semi quantitative analysis using coach focused tools such as Dartfish, Quintic and Coaches-eye (Wright et al., 2013). We suggest that the extent to which analysts themselves conduct biomechanical, physiological or psychological analysis would be somewhat limited, leaving this to sports scientist practitioners, researchers or private consultants. In fact, for clubs with larger numbers of support staff such as in the English Premier League, the performance analyst is now moving away from the physical aspect of performance, leaving this work to the 'sport scientist' (Carling et al., in press). Whilst sports scientists and strength and conditioning coaches might concern themselves with training workloads and match running data generated via Prozone and GPS for example, the performance analysts' roles will most likely be concerned with technical and tactical evaluations of performance. Clearly 
Running Title: The wider context of performance analysis and it application in the football coaching process.

information collected and provided by the likes of ProZone and Sport-Universal ( have now merged) has provided additional understanding of in-game behaviour relating to injury occurrence (Carling, Gall \& Reilly, 2010), the link between physical performance and a reduction in skill-related performance (Carling \& Dupont, 2011); and has assisted in monitoring physical load during training and competition (Strudwick 2013). Clearly, PA tools have evolved to investigate a number of sports science related issues. This rapid and dramatic evolution of PA tools might lead us to question, 'is performance analysis being misused or used more effectively?' Notably, analysis software is based on what is available not what is best for the learners (Cassidy, Stanley \& Bartlett, 2006). Furthermore, Performance Indicators (to be defined in the next section) are often measured as a result of availability rather than to develop a deeper understanding of performance (Mackenzie \& Cushion, 2012). Hence it is important that this paper begins to consider the effective, practical and conceptual use of PA in terms of its ability to generate valuable performance data, aid in providing effective feedback and delivery of data, and ensure effective transfer of information into deliberate practice / behavioural change. This is especially critical when we consider that PA tools seem to be used as a solution to multiple performance problems i.e. the 'ultimate Swiss army knife' as opposed to its initial purpose of enhancing systematic feedback and assisting performer skills learning (Collins 2012).

\section{How is performance analysis commonly used: quantitative approaches}

One of the most widely used rationales for how PA tools are used has emerged as a result of the research which has established limitations within the coaching process. These have included memory retention of key events (Franks \& Miller 1986, Franks 1993, Laird \& Waters 2008); the subjective nature of the coach's evaluation (Franks 1993); and pressure under which coaches observe performance (Hughes \& Franks 2008). Also an important yet often overlooked constraint is the limitations of the viewpoint of coaches, i.e. they are often sat on the bench, can't see everything going on. In an attempt to resolve these issues, the scope for how PA is currently used, from both an academic and practitioner perspective, has focused on the importance of providing an objective systematic quantitative evaluation of sporting performance (Carling et al., 2007). Evidence has also started to suggest PA is implemented within coaches' decision making and planning processes (Groom et al., 2011; Wright et al., 2012; Wright et al., 2013). However a more fundamental rationale for the use of PA has been described as its ability to contribute to gaining a competitive advantage (Kuper 2012), while others have proposed that PA should directly contribute to increasing the likelihood of winning games (Wooster, 2013). These factors start to raise questions on the many contextual and cultural dimensions which might impact on the coaching process (Cushion, Armour \& Jones 2006). These aspects will be discussed later in the paper. 
Running Title: The wider context of performance analysis and it application in the football coaching process.

As the systematic analysis of match performance has evolved, a substantial body of research has attempted to provide a better understanding of the importance of key quantitative parameters associated with success in football (Mackenzie \& Cushion 2012; Wright, Atkins, Polman, Jones, 2011). In order to establish the uniqueness of performance variables, notational analysis studies have previously been used to present data as ratios of goal attempts; successful, unsuccessful, percentage on target and completion rates for passing and crossing actions. To provide an indication of efficiency, analysts often present results which provide evidence for: how many times a team have the ball; how many times a team gets in the opponents penalty area; how many chances are created and how many chances are taken? Many of the early data collections placed emphasis on frequency percentages and ratio type data. 'Straight-forward' analyses, including simple frequency counts and conversion rates which provide a 'snapshot' of overall performance are of the upmost importance to practicing match analysts in elite clubs (Carling et al., 2013). Again, however, what is still not well documented is to what extent such information is simply providing a description of what is happening, i.e. 'nice to collect or nice to know', rather than providing a distinct performance advantage (Bourne, 2012). In similar fashion, Hayes (1997) originally provided an argument for establishing the impact of PA data "Show me the results of notational analysis, not the notational analysis results" (Hayes 1997 p.4). Clearly PA has been used successfully in many contexts to address the initial limitations of the coaching process as identified by the early work of Franks \& Miller (1986). As a result even a combination of the most basic objective information and descriptive feedback can prove useful in supporting the coaching process, depending on the coach and athlete's needs. In addressing Hayes' (1997) comments, evidence has also been provided to support the impact which PA can have on performance, across a range of sports (Brown \& Hughes, 1995; Jenkins, Morgan, O’Donoghue, 2007; Martin, Cassidy, O'Donoghue, 2004; Murray, Mayor, Hughes, 1998). From football evidence has also been provided by Egil Olsen (1997) on how PA impacted directly on the Norwegian national team's playing style (Olsen \& Larsen, 1997, Pollard 2002, Weaver, 2007). More recently, much of the match analysis research conducted by Carling's research group has attempted to address key performance questions within the club in which the researcher works and as a result has had a direct impact on the club's approaches and practices (Carling, Gall, Reilly, 2010; Carling \& Dupont, 2011; Carling \& Bloomfield, 2010; Carling, 2011). However little is still known as to what information derived from PA coaches do and do not value, how the information collected is used to affect their decision making and subsequent planning of training, tactical strategies and approaches. To further investigate the integration of PA generated information, it is important that we still question whether data driven approaches have been able to effectively differentiate the 'interesting to know' from the 'unique performance' variables which might be associated with the successful outcome of a game. 
Running Title: The wider context of performance analysis and it application in the football coaching process.

Identifying which factors might predict or be associated with success has become the 'Holy Grail' of PA work. As a result, PA has embraced the concept of Performance Indictors (PI's thereafter).

At this point it is necessary to make a clear distinction between academic and field work which coaches and analysts might engage with. Much of the work commented on in this and the preceding sections will be firmly situated in a research paradigm which would be described as a Positivism approach in that the academic work would often be interested in establishing a cause and effect type relationship, whereas, the investigations which coaches and analysts might employ are largely at club level and much more Interpretive in nature (Sparkes 1992). In such situations analysts and coaches will attempt to provide further interpretation to the situational factors which they face in an attempt to establish how specific issues might be impacting on their own team's performance within their own organisational context (Cushion et al., 2006; Cruickshank, Collins, Minten 2013). Clearly there is a lack of research which draws upon the application of performance analysis in a truly applied context as this will largely sit with the club themselves, thus assumptions are often drawn from academic work and applied to a practical context. The subsequent sections will attempt to consider how match and notational analysis type work has been used in football using examples from both academics and practitioners, while attempting to provide additional insight into technical and tactical elements of the game. Due to the scope of this paper physical and psychological parameters will not specifically feature.

\section{How PA is used: creation of Pls}

PI's have been widely used within the academic literature (O'Donoghue 2013) and a coaching context (Hughes, Caudrelier, James, Redwood-Brown, Donnelly, Kirkbride, Duschesne, 2012), however the term is often misused or applied to explain simple action variables, which are simple descriptors of variables commonly observed in performance i.e. 'pass success' (O'Donoghue 2013:1). The percentage of pass completion might be described as a performance indictor if it satisfies specific metric properties and is a valid measure of an important aspect of play (O'Donoghue 2013). A useful definition is provided by O'Donoghue: 'A performance indicator must represent some relevant and important aspect of play' (O'Donoghue 2010:152). Important Pl's will differ from one coach to the next (Hughes et al 2012) and as a result might lack clear operational definitions as we might expect within an academic setting. Within the academic literature (Mackenzie \& Cushion, 2012, Hughes et al 2012) and a practical context (Wright et al 2012, Wright et al 2013) there seems to be an emergence of the term Key Performance Indictors (KPl's thereafter), in an attempt to distinguish itself from basic Pl's. KPI's appear to be Pl's which are considered to be more closely aligned with success or factors associated with success for a specific team or individual. Some research has attempted to establish if Pl's can be linked with success 
Running Title: The wider context of performance analysis and it application in the football coaching process.

(winning games), or in the case of football scoring or conceding goals. In addition in a club setting analysts and coaches might use the term KPI to typify an aspect of their strategy or playing philosophy which they perceive as being central to their success (Wright et al 2012, Wright et al 2013).

Largely, the findings from PA data are presented as percentage totals and attempt to success rate ratios. However there are a number of limitations in attempting to predict future success based on past performance. The retrospective nature of PA has often been seen as a common criticism of much notational analysis type work (Hayes 1997), especially if such analysis fails to take into account current form, difficultly of fixtures played and possible injuries to key players. Although goal to attempts ratios do provide some 'normalisation' in terms of proportionality (Hughes \& Franks 2005), they still do not provide a legitimate evaluation of the chance of scoring or success and thus, have limited predictive ability. This concept was initially highlighted by Hughes and Franks (2005) reanalysis of Reep \& Benjamin's (1968) early work which promoted the use of 'route one' soccer (Anderson \& Sally 2014:20). An important concept established by Hughes and Franks (2005) was that the 'frequency of goals is not the same as the odds of a goal being scored' (Maderiros 2014:3), thus contradicting the initial findings of Reep \& Benjamin (1968) who reported that the majority of goals were scored following a short passing sequence of fewer than four passes. Reep's attempts to establish 'one general rule' for success via reductive techniques for a 'winning formula' via mechanised approach of minimal input for maximum return, resulted in missinterpretation of the significance of a direct style of play (Anderson \& Sally 2014: 21). In order to represent success as a unit of chance or probability, some attempts have been made using methods of non-linear relationship analysis such as Logistic and Probit regression. These approaches could be incorporated in order to establish odds ratios. Despite these refinements, such approaches have not been commonly used within notational analysis research until recently (Hughes 2004). One might question whether such statistical approaches have been able to attribute meaningful levels of variance ( $R^{2}$ values) associated with success in football, even given the current plethora of in-performance variables which have been investigated up until this point (Carling et al 2013).

PA analysis investigations have also been used to consider the wider parameters of football and attempt to establish the probability of Pl's predicting the likelihood of scoring (Wright's et al 2011, Ensum, Pollard, Taylor, 2004). Wright et al's (2011) findings provided insight to the probability of scoring depending on a number of contextual related factors including position of attempt, type of shot, initiation of attack and defender density to name a few (Wright et al., 2011). This work has provided evidence for, along with a number of other variables, the importance of practicing set plays because of their potential productivity in scorning goals, despite their relatively 
Running Title: The wider context of performance analysis and it application in the football coaching process.

low occurrence in comparison to open play opportunities. At the same time, however, their lack of contribution to goals scored within the logistic regression led the investigation to question how much time should be spent practicing set play routines at the expense of deliberate practice relating to open play tactics and strategies. Interesting anecdotal evidence has highlighted how Manchester City FC significantly improved their productivity at scoring and not conceding from set plays (during the 2011/12 Premier League season). It was noticed by the Manchester City analysts that the team had not scored any goals from set plays after a period of 22 games. Thus, having completed an extensive project reviewing 400 goals scored from set plays (Madeiros, 2014), and analysing a range of games across Europe, some specific coaching insights and practices were internally formulated (Fleig, 2011). Manchester City won the Carling Premier League in 2011/2012 season having scored the highest number of goals in the league from set plays; 19 goals (Premier League 2011/2012). While the example of Manchester City's practical application of PA is noteworthy, no information was provided on the amount of failed attempts thus a fuller understanding of the effectiveness of their new approach to set plays (e.g., success to failure rate) cannot be established. Moreover, It would also have been interesting to gain some insight into how this information was actually translated into specific training activities.

On a related issue, little if any consideration within the current literature, has been given to whether attempts directly on goal, via free-kicks, are the best use of such a strategic position. Unless teams have a free kick taker of the calibre of players such as David Beckham or Cristiano Ronaldo, it might be much more productive for a team to try and capitalise on their position by fashioning an attempt on goal indirectly, as an extension of open play (Kuper 2012). Because of the potential opportunity to exploit space in the penalty area and the restriction placed on the opposition (minimum of 10 yards) for the ball, the likelihood of scoring might be enhanced. Unfortunately, as in many research studies, the need to provide large data sets to ensure sufficient statistical power can often lead to the value of data being lost due to insufficient information relating to the context associated with set plays.

\section{How PA is used: The ability of PI's to reflect the dynamic nature of football.}

Early research relating to hidden patterns focused on the detection of T-patterns, which were associated with the detection of repeated temporal and sequential structures in real-time football behaviours (Borrie, Jonsson, Magnusson, 2002). Much of the work up until this point has also had a theoretical application. Although it is difficult to establish to what extent such research design is implemented, or might have an impact in an applied context, there is some evidence that such PA approaches have been implemented to allow teams to anticipate common tendencies or patterns that an opposition might exhibit. Evidence of the use of PA in such a way has been highlighted by 
Running Title: The wider context of performance analysis and it application in the football coaching process.

the German International football team, initially under the guidance of Jürgen Klinsmann. It has been suggested that evidence-based, notational analysis was implemented in developing a code book / tactical agenda for specific situational contexts (Kuper 2012). A team of analysts based at Cologne University would conduct evidence based analysis on the opposition to identify how they might exploit common behaviours, thus producing detailed reports on all opposition (Fritz 2012).

The ability of sports analysis to evaluate the role of dynamic and evolving systems in sports, specifically in this paper in football, has been highlighted by the importance of transitions in play. "Everybody says that set plays win most games, but I think it is more about transitions" - Jose Mourinho (cited in Roxburgh 2005). As highlighted by Mourinho, the ability to quickly transition from offense to defense is critical for football teams to succeed. The importance of transitions in play or counter attacks is relatively new when compared to other well established performance variables as described previously (Hughes, Dawkins, Langridge, 2000). Yiannakos \& Armatas (2006) amongst others have attempted to consider the role of counter-attacking by integrating methods of assessment within their matrix which include opposition analysis and interactions. Despite methodological challenges, PA research has most recently identified the importance of the assessment of opponent interactions while evaluating the effectiveness of offensive playing tactics (Tenga, Holme, Ronglan, Bahr, 2010). One would suggest that this is critical in improving the validity of team match-performance analysis. However, such consideration of player and opposition analysis often requires elaborate research designs which are perhaps more akin to academic than practitioner focused research. When investigating scoring opportunities against a balanced/imbalanced defence Tenga (2009) developed the criteria initially established by Olsen (1981) relating to penetration and preventing penetration during: goal scoring, winning the ball and preventing goal scorning situations (Tenga, 2009). Tenga (2009) identified that is was sometimes difficult to establish 'with certainty whether a team is in attack or defence' during specific situations i.e. when the ball is in the air or during duels, thus it was important to establish the level of possessions; 'total ball possessions and 'no ball possession' (Tenga, 2009:34) . A further important consideration when exploring imbalanced/ balanced defences is the subjective nature of such approaches (Tenga, 2010). What might be considered an unbalanced formation might be as a result of an unconventional tactic or team set up. For example, some teams may play a more risky game defensively and have a goalkeeper whose starting position is very high, almost acting as sweeper, thus raising doubts on whether the defence is actually unbalanced. Despite this, when starting to quantify football by using a more dynamic type approach as in the case and to the credit of Tenga (2009), it might be possible to begin to establish momentum throughout a game and even track a team's progression from a position of ascendency to descendency (O'Donoghue 2009). In football, the key problem remains that it is not uncommon for a team to be 'under the cosh' while the 
Running Title: The wider context of performance analysis and it application in the football coaching process.

opposition generally dominates every aspect of the game for 90 minutes and yet still win as a result of a 'lucky' goal. Thus, such work relating to momentum can be problematic when dealing with such a low scoring and fluid sport such as football (Anderson \& Sally, 2014). Similarly, it is important to point out that social and psychological aspects of play which cannot be notated are likely to greatly affect a team's flow and momentum. Despite these challenges, recent research by Lago-Peñas, Lago-Ballesteros, Alexandre, \& Gómez (2010) has used performance variables to attempt to discriminate between winning, drawing and losing in Spanish football.

Although the applications in the preceding sections have identified attempts to use PA in a more dynamic and holistic way, some of the methods of quantifying performance variables still propose a dogmatic, solvable linear algorithmic of performance problem. But because of the nonlinear nature of football, it has been proposed that new approaches which consider the sport as a more fluid and dynamic entity, should continue to be explored. Possibly the quest for the "Holy Grail' of predicting success needs to be considered from a different perspective, rather than from the simple data matrixes which have been employed up until this point. It might be worth considering we are seeking for 'multiple truths' as opposed to 'one general rule of a winning formula' (Madeiros, 2014:8). Clearly, irrespective of the analytic techniques implemented, we would propose that the most important aspects to practitioners and coaches are still how data is interpreted and actually used in interventions (Davis, 2011). It is highly unlikely that football coaches will ever understand complex statistical approaches. Coaches prefer: 'we created and took more of our chances; this season we have less possession but are creating more chances and winning more set plays from a more direct approach' etc (Carling et al., in press). In order to enhance the interpretation and use of the data it might also be worth contemplating how the quality, rather than the quantity of the data may be improved by a deeper understanding of appropriate context specific information. This paper is not trying to suggest that there is a problem with contemporary PA but simply to make the case that future research would be beneficial especially if it was able to further establish the extent to which such PA information impacts on practices and systems within football clubs' everyday practice. In other words does it affect short term /long term planning in terms of specific practice, but also the development and/or recruitment of players to fulfil the specific needs of a club.

\section{The importance of contextual information in enhancing the meaningfulness of the data.}

This section explores how PA data might be used to establish trends, thus allowing coaching and support staff to generate and address effective performance-related questions. As highlighted in the previous section, academic research is evolving to address some of the challenges which exist in terms of the ability of the discipline to move from a very restrictive linear analysis of 
Running Title: The wider context of performance analysis and it application in the football coaching process.

performance to one which can provide further insights into the non-linear, dynamic and evolving nature of football. In order to move towards approaches which provide insightful understanding to football, it might be worth exploring the importance of wider contextual information in which data are currently set. The evolution in the amount and type of quantitative data available surrounding PA analysis over the last 20 years has been dramatic (Anderson, 2013). This has been created from a number of different perspectives, most commonly from academic publications in sports science, coaching science related journals and practitioner focused journals such as Insight (The Football Associations Coaching Journal). More recently, PA has been presented and discussed in the commercial and blogger spheres. In a relatively short period of time, we have moved from nothing to everything in terms of assessment of match play: there is clearly 'nowhere to hide' on the pitch (Carling et al., 2007). For example, OPTA Sport (Sports Data Company), in collaboration with Manchester City Football Club, recently released a dataset containing all English Premier League football matches from the 2011/12 season (see http://www.mcfc.co.uk/the-club/mcfc-analytics). Furthermore, blogger mediums have provided new insight into sports performance, using a combination of match data via open sources such as the English Premier League Index (http://www.eplindex.com). These have resulted in critical but usually subjective fan analysis which is (apparently) well supported and grounded in objective notational analysis data. Accordingly, what many of the insightful bloggers have been able to do (e.g., The Liverpool Supporting Atmospheric Scientist) is provide important context around this key objective data. Clearly, more and more data is available from a range of different sources. What is often additionally required however is contextual intelligence in order to provide more quality insights.

In order to further investigate the role of important contextual information, it might be worth exploring the example of the importance and potential misinterpretation of possession within professional football. In the case of Premier league football and International Tournaments, possession of the ball does not appear to be a key performance indicator which could associated to scoring goals (Hughes \& Franks, 2005, Jones et al., 2004, Bate, 1988, Stanhope, 2001). As a result, one might explore other outcome variables which might be considered as providing a more longitudinal look at performance. For example, league standing might be worth exploring, as opposed to just goals scored. In this regard, one could speculate that the recent domination of Spain at international level and Barcelona at club level, have largely been attributed to their ability to retain possession for prolonged periods of time, with Barcelona averaging $73.4 \%$ in La Liga and $74.3 \%$ in the Champions league in $2010 / 11$ (Prozone, 2011). This might suggest that keeping the ball for sustained periods of time in the modern game will lead to success. Moreover, more recent analysis of international football found that successful teams utilised longer periods of possession 
Running Title: The wider context of performance analysis and it application in the football coaching process.

compared to unsuccessful teams (Successful team: team which progressed to the knockout stages) (Prozone, 2011; Lago-Peñas et al., 2010; Garganta, 2009). In contrast, however, the evidence might suggest that, although teams who finish in the top six (during 2010/11 Premier League seasons) had longer periods of possession compared with unsuccessful teams, retaining possession may not be a decisive variable to distinguish who finished with the most or least points within the Premier League (Prozone, 2011; Hughes \& Franks, 2005).

Accordingly, in order for the value of possession, as in the case of many other performance variables, to be genuinely meaningful to the coaching process, a further understanding of the wider aspects of possession seems essential. For example, in order to further consider if possession plays a role in predicting a successful outcome for a team, further consideration to the quality of possession in the opposition half or final third might be needed. This might lead us to reframe the initial question to: 'does more decisive possession lead to a goal scoring opportunity rather than the amount of possession (Lago-Peñas et al., 2010; Jones et al., 2004)?' In the case of Barcelona, analysis of possession might not reflect their ability to retain and win back possession. The ability of teams such as Barcelona or even Spain to make a deliberate effort to chase down the ball or challenge for the ball in a specific time frame from losing possession might be a more important or parsimonius context-related variable, which might assist in explaining their dominance of possession.

This point might lead us to question if the way in which possession is measured and assessed is too crude, thus are these aspects identified above too subtle to quantify? Are there specific passing networks occurring between specific players which are more productive than others (Gurpinar-Morgan, 2012)? Other important wider contextual factors might include: the opposition's system of play; home advantage; current score line; significant officiating decisions (Carling et al., 2013). Again, these contextual factors might play an important role in the collection, analysis and interpretation of a number of performance variables. Other context specific variables relating to possession might include the quality of ball control to take to make time and space, i.e. does it result in a forwards or backwards movement, does it allow the player the ability to progress the ball forward, thus maintaining momentum? In the case of Carling's (2010) study, which investigated player separation in relation to their team mates and the nearest opposition, it would have been interesting to know if this was influenced by the quality or tactics of opposition (is there a link between team quality and their ability to disrupt play). Are teams which deliberately try to close down space or pressurise the opposition successful in disrupting the quality of the opposition's possession? Are some teams 'better' at this than others? All these potential qualitative factors could be systematically assessed if clear operational definitions are created prior to inter / intra observer reliability being established. For effective implementation, all operational definitions would have to 
Running Title: The wider context of performance analysis and it application in the football coaching process.

be established and agreed upon by the coaching and support team involved in the analysis process. However this is not always common practice in some football clubs. Also this might be a problem when using match analysis providers whose own definition sets might not align with the club's definitions. Clearly, when we discuss the importance of wider contextual information, on one hand, we are referring to the importance of evaluating the wider antecedents (cause) and outcomes (results) associated with a specific behaviour. But in addition, we might also want to consider wider contextual factors which might directly impact on the antecedents, behaviour and outcome. Significant situational variables have been identified as impacting on performance, these included: Game location (home and away advantage), quality of opposition, game period and type of competition (Gómez, Lago- Peñas, Pollard, 2013). Although the scope of this paper is not able to discuss each of these case by case, evidence has suggested all these situational variables have an impact within football to some extent (for a detailed review of these factors, the reader is referred to the work of Gómez et al., 2013). Situational variables might be even more pertinent when we consider the low scoring nature in football and the lack of control over the 'ebb and flow' of the game as we would see in other sports, where the coaches are able to use time outs at strategic times to impact on the momentum of the game. As a result the nature of football makes it extremely difficult to transfer strategic information to players during the game (Gómez et al., 2013). It is also important to give consideration of the extent to which situational factors might interact, and thus impact on Pl's and the outcome of the game. A number of 'higher-order interactions' (Gómez et al., 2013:264) have been identified in football. Lago (2009) established interactions between possession, match location and match status, with home teams having more possession when drawing than away teams (Gómez et al., 2013). Taylor, Mellalieu, James, Shearer, (2008) reported that the frequency of common action variables (pass, shot, tackle, clearance, crosses, dribbles, loss of control and aerial challenges) were also impacted upon by match location and match status. Finally, Lago, Casais, Dominguez, Sampaio, (2010) established the effect of match location, quality of opposition and match status on running activity. These key examples provided the importance of considering the interactional effect of situational variables on performance.

\section{The role of 'None Stat All Stars' and less measured variables}

To extend the points made in the previous section, we further hypothesise that wider contextual information is key when we consider the role of 'None Stat All Stars'. These are a group of individual players who play a pivotal role in the success and even failure of a team, but whose contribution might not be fully appreciated within current game analysis (Wooster 2013). The concept of measuring the intangibles is not new when attempting to provide a wider and more holistic view of analysis. But often such intangibles might still not have been well represented in current statistical matrixes. Often, analysis in its wider application of sports science can place too 
Running Title: The wider context of performance analysis and it application in the football coaching process.

much value on the aspects which we can most readily quantify, thus ignoring the ones which we cannot and/or which are difficult to ascertain (Kiely, 2011). Potentially, the ones which are the most difficult to quantify could be the most important or insightful (Kiely, 2011, Wooster, 2013; Madeiros, 2014). PA could provide information relating to the consistency of specific teams and individuals, for example are higher ranked teams more consistent in certain areas of performance, although can be difficult to measure due to changes in playing and coaching staff. Experienced analysts might track such information over a number of seasons but also make comparisons at critical parts of the season (Hatton, 2013; Lawless 2013). Similarly, the focus of PA has often not given consideration to defending and its significance within the current literature. Clearly, there are a number of practical issues associated with quantifying off-ball parameters. But the importance of the 'last ditch tackle' or that 'crucial block' might be critical in interpreting not only defensive effectiveness, but also in explaining a lack of attacking effectiveness. In match analysis systems, 'Duel' or 50/50 confrontation might be coded as a tackle (Gerisch \& Reichelt 1993). The ability of a defender to dominate such situations might also be under represented, due a lack of sensitivity in the analysis tool. We often find that attacking duels are not differentiated form defending duels in the stats. Additionally, this might highlight the need for individualised player ratings according to player roles. If we take, for example, Bolton Wanders Football Club (when in the Premier League under the management of Sam Allardyce) one could speculate that they had a specific set of criteria, based more on direct play, 'in your face' pressing in the final third of the pitch. In contrast, teams such as Manchester United might look more at their ability to counter attack.

Although consideration of many of these factors would provide further insight into game analysis, there is always a 'cost to effectiveness' equation to be considered in terms of the time requirement of conducting such analysis, especially when accounting for contextual factors. Such context-rich analysis would have to be central to assisting the effectiveness of a coach's coaching philosophy, and aspects of strategy which coaches or organisations might associate with success. Notably, however, evidence suggests that many coaches still base their team performance evaluation on 'hunch' or 'gut instinct' (Anderson \& Sally 2014, Kuper \& Szymanski 2012), thus reinforcing their decision making process through being driven by tacit rather than declarative knowledge (Nash \& Collins 2006; Edgar 2013b). The ability of PA to resolve specific performance questions which directly inform the coaching process might be dependent on the coaches' ability to clearly articulate and operationalize what they associate with success in football. This clearly might be a concept which some coaches will struggle with (Anderson 2013). If coaches are unable to do this, one might start to question if any such analysis can come to fruition and thus translate into an adequate form for informing their coaching practice. An important concept, not explored in the current literature is the extent to which practitioners will utilise a balance of video to represent 
Running Title: The wider context of performance analysis and it application in the football coaching process.

important Pls during the game and statistics information. It is anticipated that most analysts using statistical data will be linked to specific video instances, which would provide important contextual information relating to the antecedence, behaviour and consequence. An important question might be, do statistics initially lead the coach to seek insight from the video or alternatively, would video be observed first then followed by statistics to support the coaches' initial observations?

At this point another important question might be to consider where the stimulus for analysis should lie; does the responsibility lie with the coach or the analyst team? Would we expect the coach to be proactive in setting specific performance related questions or is it the role of the analyst to proactively provide insight which the coach has not previously considered, was aware of or raise performance questions which the coach has not even contemplated? As the responsibility of analysts have evolved as a result of developing effective working relationships with the coaching team and managers, it is not uncommon in some clubs for coaches to leave Pl's choice up to the analysts, thus the latter also take the initiative to analyse other aspects of play which they feel are appropriate (Carling et al in press).

\section{The growing constraints which PA face}

At this point it would be speculative to draw upon how performance analysis might be effectively delivered and used when we consider the current lack of empirical imperial evidence (Mackenzie \& Cushion, 2012). In order to further understand its purpose and impact, attempts should be made to unpick the pedagogical bases for its use by coaches and the possible constraints which influence its implementation. This concluding section will consider some of the most obvious constraints which relate to the application in PA approaches.

There are a number of texts which provide theoretical models that relate to the conceptual use of PA tools and approaches (Carling, Williams, Reilly, 2005; Hughes \& Franks, 2004) Refer to figure 1.1. These have been central in providing initial insight to undergraduate students and

aspiring analysts in an attempt to understand the process of the coaching cycle and how the performance analyst might support such a process. However despite their practical use, such flow charts and schemas of the coaching cycle have been highlighted as presenting an idealistic and simplistic view of performance in terms of observation, planning, training and practice (Groom et al 2011). Also they potentially fail to take into account the complex and problematic nature of developing performance in a changing and fluid highly competitive environment (Cushion et al., 2006, Lyle, 2002). What has become apparent most recently is evidence for increased use of PA in assisting the coaching process, with not only a growth in positions available (paid and unpaid) but also a change in the diversity and variety of the types of roles which analyst might be required to 
Running Title: The wider context of performance analysis and it application in the football coaching process.

fulfil while using video editing technology in and around professional football teams (Hatton 2013; Carroll 2013, Wright et al. 2013). In the English Premier League it is not uncommon for contemporary analysts to report a working week of 60 hours, as they frequently travel with the 1st team which can be extremely time-consuming and tiring. These factors place additional pressures on their ability to turn the game analysis around quickly and effectively (Carling et al In press). Despite huge workloads many of these roles are still poorly paid. Some clubs now have the means and willingness to employ analysts working at distance to conduct such analysis. A more proactive approach to game analysis might enhance a club's ability to address questions from an evidence based approach, thus taking a more long term look at performance (trends over a continual 4 week cycle). Some clubs appear to be fairly well supported in terms of performance analyst support, with analysts fulfilling specific roles relating to recruitment analysts, opposition analysts, academy analysts and first team analysts (Hatton 2013, Wright et al., 2013, Carling et al In press). But the effectiveness of these roles will possibly be influenced by their integration within the wider organisation. A lack of integration with the coaching team and wider organisation can result in localised analytics (Davenport \& Harris 2007; Bourne 2012, Madeiros, 2014), where even the most insightful analysis and interpretation of data will not see the 'light of day' if it is not received or used by anyone outside the analyst team. This might be a potential constraint or barrier to PA which warrants further consideration. One of the potential restrictions which might affect the interaction of performance analysis is the extent to which the wider organisation values the importance performance analysis has and, as a consequence, the financial constraints in place which prevent sufficient levels of support (Wright et al., 2012, Madeiros, 2014). In a high performance environment we might expect a performance manager to give clear guidance retaining to agreement, alignment, accountability and adjustment for effectively implementing PA in supporting wider analysis activities (Wiltshire, 2013). However evidence had suggested less formal methods of mentoring and support are accepted within football (Grecic \& Collins 2013; Partington \& Cushion 2013), and also that role clarity is often a challenge within the coaching process resulting in a number of levels of ambiguity and uncertainty (Jones \& Wallace 2005). This in turn highlights the importance that further consideration is given to the specific and effective integration of analysis within a specific organisation and their coaching process.

The openness of football clubs to share and publish work relating to their integration with PA has often been limited. Possibly, analysts working within clubs have seen the information they produce as being predominantly relevant to their own specific applied context, thus limiting their motivation to publish such findings (Durst 2010). This might be akin to the secretive Research and Development projects as we might see in traditional industries where research findings are considered too important to be published due to the advantage or 'unique selling point' they might 
Running Title: The wider context of performance analysis and it application in the football coaching process.

provide for their company. Despite this, case studies and action research type inquiry might be essential in providing important insight in the exemplar use of PA in an applied context (Mackenzie \& Cushion 2012, Nelson \& Groom, 2011). A move to a more interpretive naturalistic even qualitative type approach would most likely provide a better understanding of the effective use of PA (Mackenzie \& Cushion 2012). This might provide useful insight into how different teams, organisations, mangers and coaching teams might adapt their approach to meet their own and the external needs which they face. Such a fluid and flexible approach to analysis might not be reflected in the conceptual models previously identified, which fail to represent the fluid and changing nature of the coaching environment (refer to figure 1.1). Groom's et al., (2011) grounded approach to the delivery of video-based performance analysis highlights the use of video-based PA as being subject to a number of complex social interactions between coach, analyst and players. In order to provide examples of the exemplar use of PA it would be imperative to firstly better understand 'the complexities of the dynamic, psychological and social activities' which surround the use of PA (Groom et al., 2011:30). Groom et al., (2011) provided a strong rationale for further consideration as to how the social environment, coaching / delivery philosophy and recipients' qualities might frame the delivery process. Any proposed intervention of video analysis requires careful consideration of presentation format, session design and delivery approach and targeted outcome (Groom et al., 2011).

One of the common criticisms, which could be considered to limit the impact that PA can have within domestic football, is a club's inability to look past a short-term approach. As a result, some clubs' approach to analysis seems to focus on a game to game approach (Wright et al., 2012). However such a short-term approach is synonymous with the result based business elite football coaches find themselves in. Unless coaches are $100 \%$ sure that PA will have a positive impact, and preferably an immediate impact, they might be reluctant to invest the time needed (Wooster, 2013). This is understandable when we consider the average life span of a football manger across all 4 professional levels in England is 1.7 years (Bridgewater, 2012) and, at all levels of the domestic game, promotion and relegation places are at stake. These issues are magnified when we consider the heavy fixture schedule of certain clubs and bunching of fixtures at key times of the seasons. As a result, PA focus in a team could be more heavily weighted to an assessment of the opposition (pre-match focus) thus investigating how the opposition's weakness might be exploited and strength minimised, as opposed to looking at an assessment of the team's own performance (post-match focus). But again a deeper understanding of why such approach's might be adhered to, would require detailed exploration of the coach's coaching philosophy and how this has shaped the implementation of their strategy and tactics. 
Running Title: The wider context of performance analysis and it application in the football coaching process.

Clearly, some coaches invest significantly more time in order to gain a comprehensive understanding of performance problems using match performance data, reports and videos (Wright, 2012). In other contexts, some experienced and very successful football coaches might rely more on their personal judgment and intuition (Edgar 2013b; Madeiros 2014). During periods of pressure, the filtering of critical features is essential for timely and effective decision making. Fundamental to this approach is the ability of the coach to establish an effective 'theory of the game', i.e. know what wins games, or have a strategy they associate with winning games. Also crucial, however, is the coach's ability to articulate this to their support team. This might be an alien concept to many coaches (Anderson, 2013), as such conceptual thinking is not central to formal coach education systems. Effective and responsive communication might also be essential when there is every possibility that performance parameters might change and be modified as more reactive type problems present themselves (Wright et al., 2012). Up to this point what has not been fully explored is how coaches make their decisions in relation to assessing performance, what performance parameters are used to assess against and how this influences their interpretation of the game. One would suggest a deeper understanding of these factors and would be central to establishing how Pl's are established and implemented.

What is not well understood is how the relationship and dynamic process in place between the coach and analyst allows effective analysis to be produced and thus provide insight into performance within the subsequent training week. Although we would hypothesise that the relationship and communications process are central to the effective use of PA this still remains an unknown when we consider the current research gaps. Although shared mental models have been identified as being central to the coach and athlete relationship (Mascarenhas \& Smith, 2011), it would be interesting to establish if a shared mental model exists between the head coach and the wider coaching and support team, in relation to their shared values, beliefs and coaching philosophy. Also what might be the extent to which a shared mental model is central in identification of critical performance features and filtering out non-essential aspects to ensure that individuals are not overloaded with enormous amounts of information (Mascarenhas \& Smith, 2011). Preceding research has identified the central importance of 'trust' and 'respect' when considering the varied interactions between the coach and key stakeholders (e.g. athletes, assistant coaches, parents, administrators) in their respective coaching contexts (Potrac, Jones, Amour 2002; Jones, Armour, Potrac 2004; Cushion \& Jones, 2006; Potrac \& Jones, 2009, Wiltshire, 2013). Groom et al., (2011), further identify the importance of respect between coach and player in order to ensure interpretation of the coach's decisions and behaviours when reviewing video-based feedback. Further understanding in such areas is also further warranted. Evidence has suggested that a high performance environment should promote an athlete focused environment (Wiltshire 
Running Title: The wider context of performance analysis and it application in the football coaching process.

2013) where approaches are employed to promote players' own learning and development (Hodges \& Franks, 2004, Ford, Yates, Williams, 2010; Collins 2012). Although we might envisage that PA could play a central role in players' own self-analysis and development, very little is currently known as to what extent coaches' approaches would facilitate effective PA feedback.

Clearly, careful consideration should be given as to how and when information might be best delivered to the players to enhance its impact, 'ultimately, a good performance management and analysis tool is not just a control mechanism but a learning system that effectively communicates and informs' (Wiltshire 2013:180). Although feedback plays a critical role in facilitating learning (Vickers, 2011), both coach and analyst alike must be aware of its limitations and the problematic nature of effective feedback. Research surrounding feedback has suggested that performers can become too reliant on feedback and thus it suppresses the performer's ability to identify faults (error detection) and correct faults (error correction) themselves (Hodges \& Franks, 2008). As Wright et al., (2013) have highlighted, the performance analysts themselves play a very varied role in terms of the feedback and debriefing of information to the manager, wider coach team and players. What is not currently explored in the literature is to what extend coaches, and analysts understand the complexities in which they might have to consider when and where feedback is or is not implemented. This is an issue which again might be considered as being central to the effective delivery of video and PA analysis process, but again the literature has only just started to unpick some of the pedagogical issues which might need to be considered when implementing PA approaches (Groom et al., 2011).

\section{Conclusion}

In a relatively short period of time there has been a dramatic growth in the range and depth of academic research and the applied application of PA within the field by practitioners. As a result huge amounts of data are often generated by contemporary PA techniques and systems. Strong evidence has been provided for PA's ability to provide objective information to enable useful insight and understanding of technical and tactical Pls central to football performance. Similar evidence has emerged that such information has an important role to play in enhancing the coaching process. On the basis of such useful and valid evidence we are not trying to make out there is a problem with how PA is currently used from an academic and applied perspective, but what has been highlighted in this paper is the importance of continual development to provide and apply contextual intelligence to the quantitative data which is generated, to further enhance its meaning and impact. This is critical to ensure that the insight which data can provide allows for differentiation between general and unique performance parameters. The addition of more qualitative type enquires and case studies of real performance problems which football clubs face might provide some insight into the 
Running Title: The wider context of performance analysis and it application in the football coaching process.

potential pedagogical underpinning and subsequent effective implementation of PA. Despite the plethora of PA research, little is known relating to how information is effectively transferred to all parties involved with the PA process. Even less evidence is openly documented regarding how data is transferred to impact on planning and specific training sessions and interventions. As a discipline, to further establish the impact or effect PA might have on the coaching process and ultimately performance we call for a better comprehension on a number of the factors identified above. 
Running Title: The wider context of performance analysis and it application in the football coaching process.

\section{References}

Anderson, C. (2013). Football Analytics. The MIT Sloan Sports Analytics Conference. Boston, March 2013. Available on line at: http://www.youtube.com/watch?v=2Ye-mvV9ELI

Anderson, C. \& Sally, D. (2014). The numbers Game: Why everything you know about soccer is wrong. Penguin Books: New York.

Armatas, V., Yiannakos, A., Papadopoulou, S., \& Galazoulas, Ch. (2007). Analysis of the setplays in the $18^{\text {th }}$ football world cup in Germany. Physical Training, October.

Bartlett, R. (2001). Performance analysis: can bringing together biomechanics and notational analysis benefit coaches? International Journal of Performance Analysis of Sport. (1), 1,122126.

Bangsbo, J. \& Peitersen, B. (2000). Football systems and strategies. Human Kinetics: Champaign, IL.

Bate, R. (1988). Football chance: Tactics and Strategy. In T. Reilly, A. Lees, K. Davids, \& W Murphy (Eds.), Science and Football. E \& FN Spon. London. 293-301.

Bishop, D. (2003). What is performance analysis and how can it be integrated within the coaching process to benefit performance. Peak Performance, April, 4-7.

Borrie, A., Jonsson, K., \& Magnusson, S. (2002). Temporal pattern analysis and its applicability in sport: An explanation and exemplar data. Journal of Sports Sciences, 20,845-852.

Bourne, M. (2012).The role of Performance analysis within ECB. Sports Analytic Conference: The Sports Office November 2012. Manchester University Business School. Accessed on 16/02/2012. Available online at: http://www.youtube.com/watch?v=b91 VB7bPMg

Bradley, P., Lago-Peñas, C., Rey, E. \& Diaz, A. (2013). The effect of high and low percentage ball possession on physical and technical profiles in English FA Premier League Football matches. Journal of Sports Science, 22, 1466-1447.

Bridgewater, S. (2012).2011 - 2012 Season Statistics: LMA Football Manager Statistics. Accessed 24/05/12. available on-line at: http://www.leaguemanagers.com/media/lmaseasonstats.pdf

Brown, D. \& Hughes, M. (1995). The effectiveness of quantitative and qualitative feedback on performance in squash. In T. Reilly, M. Hughes and A. Lees (eds), Science and Rackets Sport (pp.232-7). London: E and FN Spon.

Carling, C. (2012). The role of a contemporary performance analyst. Institute of Coaching and Performance, Guest Seminar. University of Central Lancashire. Preston. $5^{\text {th }}$ December, 2012.

Carling, C. (2010). Analysis of physical activity profiles when running with the ball in a professional football team. Journal of Sports Sciences, 28, 319-328.

Carling, C., \& Bloomfield, J. (2010). The effect of an early dismissal on player work-rate in a professional soccer match. Journal of Science \& Medicine in Sport, 13, 126-128.

Carling C, Gall FL, Reilly TP. (2010). Effects of physical efforts on injury in elite soccer. International Journal Sports Medicine. Mar;31(3):180-5

Carling, C. (2011). Influence of opposition team formation on physical and skill-related performance in a professional soccer team. European Journal of Sports Science. 11 (3): 155-164.

Carling, C. \& Dupont, G. (2011). Are declines in physical performance associated with a 
Running Title: The wider context of performance analysis and it application in the football coaching process.

reduction in skill-related performance during professional football match-play? Journal of Sports Sciences, 29 (1):63-71.

Carling C, Gall FL, Reilly TP. (2010). Effects of physical efforts on injury in elite football. International Journal Sports Medicine. Mar;31(3):180-5.

Carling, C., Reilly, T., Williams. M. (2009). Performance Assessment for Field Sports. Routledge: London

Carling, C., Wells, S., \& Lawlor, J. Performance analysis in the professional football club environment. In W. Gregson \& M. Littlewood (Eds.), Science in Football: Translating Theory into Practice. Bloomsbury. Publishing, in press.

Carling, C., Williams, M.A. and Reilly, T. (2007). Handbook of football match analysis. Routledge: London.

Carling, C., Wright, C., Nelson, L., Bradley. P. (2013) Comment on 'Performance analysis in football: A critical review and implications for future research'. Journal of Sports Sciences. In Press.

Carroll, R. (2012). An Expert Guide to Performance Analysis E-book. Thevideoanalyst.com. Accessed on 18/11/2013. Available online at: http://thevideoanalyst.com/

Cassidy, T., Stanley, S., Bartlett, R. (2006). Reflecting on Video Feedback as a Tool for Learning Skilled Movement. International Journal of Sports Science \& Coaching, (1), 3, 276288.

Collins, D. (2012). Useful Tool of Swiss Army Knife. Sports Analytic Conference: The Sports Office November 2012. Manchester University Business School. Accessed on 16/02/2012. Available online at: http://www.youtube.com/watch?v=CipqiigPw40

Cushion, C. J., Armour, K., \& Jones, R. L. (2006). Locating the coaching process in practice: Models "for" and "of" coaching. Physical Education and Sport Pedagogy. 11, 83-99.

Cushion, C. J. \& Jones, R. L. (2006) Power, discourse, and symbolic violence in professional youth soccer: the case of Albion Football Club, Sociology of Sport Journal, 23, 142161.

Cruickshank, A., Collins, D., Minten, S. (2013). Culture Change in a Professional Sports Team: Shaping Environment Contexts and Regulating Power. International Journal of Sports Science and Coaching, (8),2, 271-290.

Davis, C. (2011). Assessing the Game at Swansea City. Chris Davies Head of Analysis explains how Match Analysis works at Swansea City and how it plays an important part for the team (2010/2011). Available online at: http://www.youtube.com/watch?v=9 1Dx3wgCP8

Davenport , T. \& Harris, J. (2007). Competing on analytics the new science of winning. Harvard business School: USA.

Durst, B. (2010). Editorial: Performance analysis research: Meeting the challenge. Journal of Sports Sciences. July, 28(9): 921-922

Duckett, J. (2012). Objectivity in Analysis: Performance Analysis of Football. The Football Association. Available on line at: http://www.thefa.com/st-georges-park/discover/coaching/licensed-coaches-club/latest-fromthe-Icc/more-news/objectivity-in-analysis

Edgar, S. (2013a). Interview: Sam Allardyce Talks Performance Analysis. Prozone Sports Ltd. Available online at: http://www.youtube.com/watch?v=dgVhQImfwXM\&feature=c4overview\&list=UUgUO4NVP3chJTuHk5lwJx9w

Edgar, S. (2013b). Interview: Roberto Martinez Talks Performance Analysis. Prozone Sports Ltd. Available online at: http://www.youtube.com/watch?v=XxGaqLPyL I

Ensum, J., Pollard, R., \& Taylor, S. (2004). Applications of logistic regression to shots on 
Running Title: The wider context of performance analysis and it application in the football coaching process.

goal in association football: Calculation of shot probabilities, quantification of factors and player/team. Journal of Sports Sciences,(22), 504.

Fleig, G (2011). Football Analytics. The MIT Sloan Sports Analytics Conference. Boston, July 2013. Available on line at: http://www.sloansportsconference.com/?p=626

Franks, I. (1993). The effects of experience on the detection and location of performance differences in a gymnastic technique. Research Quarterly for Exercise and Sport, (64), 2, 227-231

Ford, P., Yates, I. \& Williams. (2010). An analysis of practice activities and instructional behaviours used by youth soccer coaches during practice: exploring the link between science and application. Journal of Sports Sciences, 28 (5): 483-495.

Franks, I. Miller, G. (1986) Eyewitness testimony in sport. Journal of sport behaviour,(9),3945.

Fritz, O. (2012). UEFA Euro 2012: Scouting for the German team. 21/06/12. Available on line at: http://www.dw.de/scouting-for-the-german-team/a-16040814

Garganta, J. (2009) Trends and tactical performance analysis in team sports: bridging the gap between research, training and competition. RevistaPortugesa de Ciencias do Desporto, (9), 1.

Gerisch, G. \& Reichelt, M. (1993). Computer and video aided analysis of football games. In T. Reilly, J. Clarys and A. Stibbe (eds), Science and Football II London: E\&FN Spon. 167-174.

Glazier, P.S. (2010). Game, set and match? Substantive issues and future directions in performance analysis. Sports Medicine. 40, 625-634.

Gómez, MA., Lago-Peñas, C. \& Pollard, R. (2013). Situational Variables. In T. McGarry, P. O'Donoghue \& J. Sampaio (Eds), Routledge Handbook of Sports Performance Analysis. Routledge: Oxon, 259-269.

Grecic, D. and Collins, D. (2013). The epistemological chain: practical applications in sports. QUEST, 65, 2, 151-168.

Groom, R., Cushion, C. J. \& Nelson, L. J. (2011). The delivery of video-based performance analysis by England youth football coaches: towards a grounded theory. Journal of Applied Sport Psychology. 23, $16-32$.

Gurpinar-Morgan, W. (2012). West Bromwich Albion vs Liverpool: passing network analysis. $2+2=11 \mathrm{~A}$ football blog revolving around numbers: Focus often on Liverpool F.C. 15/08/2012. Available on-line at:

http://2plus2equals 11.wordpress.com/2012/08/21/west-bromwich-albion-vs-liverpoolpassing-network-analysis/

Hatton,L.(2013). An interview with Prestidge is the Head of Performance Analysis at Bolton Wanderers. SB Nation: Fanpost. Available online at: http://lionofviennasuite.sbnation.com/2013/6/10/4414800/data-analysis-shaping-football-andbolton-as-they-enter-new-territory

Hayes, M. (1997).Notational analysis - the right of reply. BASES Newsletter, 7(8), 4-5.

Hodges, N.J. \& Frank, I.M. In M. Hughes \& I. Franks (Eds.), The essentials of Performance Analysis An Introduction. London: Routledge, 2008, 21-39.

Hughes, M. \& Bartlett, R. (2002). 'The use of performance indicators in performance analysis. Journal of Sports Science. 20:739-54.

Hughes, M. (2004). Performance analysis - a 2004 perspective. International Journal of Performance Analysis in Sport. 4,1,103-109. 
Running Title: The wider context of performance analysis and it application in the football coaching process.

Hughes, M., Caudrelier, T., James, N., Redwood-Brown, A., Donnelly, I., Kirkbride, A. \& Duschesne, C. (2012). Moneyball and Soccer - an analysos of the key performance indicators of elite male soccer players by position. Journal of Human Sports \& Exercise, 7,2,402-412.

Hughes, M. \& Franks, I. (2008). The essentials of Performance Analysis: An Introduction. London: Routledge.

Hughes, M., \& Franks, I., (2005). Analysis of passing sequences, shots and goals in football. Journal of Sports Sciences, 23, 509-514.

Hughes, M., Dawkins, N. \& Langridge, C. (2000). 'Perturbation not leading to shots in football'. In M. Hughes (Ed), Notational Analysis of Sport III, Cardiff: CPA, UWIC. 108-16.

Jenkins, R., Morgan, L. \& O'Donoghue, P. (2007). 'A case study into the effectiveness of computerised match analysis and motivational videos within the coaching of a league netball team. International Journal of Performance Analysis of Sport, 7 (2):59-80.

Jones, W. (2013). Performance Analysis Employment: Prozone Analysis. The Video Analyst.com. Available online at: http://thevideoanalyst.com/performance-analysis-employment-will-jones/

Jones, R.L. \& Wallace, M. (2005). Another bad day at the training ground: Coping with ambiguity in the coaching context. Sport, Education \& Society, 10(1), 119-134.

Jones, P., James, N. and Mellalieu, S.D. (2004). Possession as a Performance Indicator in Football. International Journal of Performance Analysis in Sport 4(1), 98-102.

Jones, R., Armour, K. \& Potrac, P. (2004) Sports coaching cultures: from practice to theory. London: Routledge.

Kiely, J. (2011). Planning for physical performance: the individual perspective. In D. Collins,

A, Button, H. Richards (Eds.), Performance psychology a practitioner's guide.

Churchill Livingstone Elsevier, London, 140-159.

Kuper, S. (2012). Football Analytics: The Money Ball of Football, an outsiders perspective.

Sports Analytic Conference: The Sports Office November 2012. Manchester

University Business School. Accessed on 16/02/2012. Available online at:

http://www.youtube.com/watch?v=YaTALljKvAQ

Kuper, S. \& Szymanski, S. (2012). Soccernomics. HarperSport:London.

Lawless, M. (2013). EXCLUSIVE: Big Sam is 100 not out... and we reveal how life at West Ham is a numbers game under Allardyce. The MainOnline. Available at:

http://www.dailymail.co.uk/sport/football/article-2430369/Sam-Allardyce-100th-West-Hammatch-Sportsmail-reveals-life-Hammers-numbers-game-Big-Sam.html

Lago-Peñas, C., Lago-Ballesteros, J., Alexandre, D., Gómez, M. (2010) Game-related statistics that discriminated winning, drawing and losing team from the Spanish football league. Journal of Sports Science and Medicine (9), 288-293.

Lago, C. (2009). The influence of match location, quality of opposition, and match status on possession strategies in professional association football. Journal of Sports Sciences, 27: 1463-1469.

Lago, C., Casais, L., Dominguez, E., Sampaio, J. (2010). The effects of situational variables on distance covered at various speeds in elite soccer. European Journal of Sports Science, 10: 103-109.

Laird, P. Waters, L. (2008) Eyewitness Recollection of Sports Coaches. International Journal of Performance Analysis, (8), 1, 76-84.

Lyle, J. (2002). Sports coaching concepts: A framework for coaches' behaviour. London: Routledge. Madeiros, J (2014). The winning formula: data analytics has become the latest 
Running Title: The wider context of performance analysis and it application in the football coaching process.

tool keeping football teams one step ahead. Wired Magazine. January. Available one line at: http://www.wired.co.uk/magazine/archive/2014/01/features/the-winning-formula

Mackenzie, R., \& Cushion, C. (2012).Performance analysis in football: A critical review and implications for future research. Journal of Sports Sciences, 31, 639-76.

Martin, D., Cassidy, D. \& O'Donoghue, P. (2004). The effectiveness of performance analysis in elite Gaelic football, World Congress of Performance Analysis of Sport 6, June.

Mascarenhas, D. \& Smith, N. Developing the performance brain: decision making under pressure. In D. Collins, A. Button, H. Richards (Eds.), Performance psychology a practitioner's guide. Churchill Livingstone Elsevier, London. 2011, 245-269.

Murray, S., Mayor,D. \& Hughes, M. (1998). A preliminary investigation into the provisions of computerised analysis feedback ti elite squash players. In A. Lees, I. Maynard, M. Hughes and T. Reilly (eds), Science and Racket Sports 2 (pp.235-40). London: E \& FN Spon.

Nash, C. \& Collins, D. (2006). Tacit Knowledge in Expert Coaching: Science or Art? Quest, (58), 465-477.

Nelson, L., Potrac, P., \& Groom, R. Receiving video-based feedback in elite ice-hockey: a player's perspective. Sport, Education and Society.1-22,iFrist.

O'Donoghue, P. (2013). Editorial: The Use of Intern Analysts \& Volunteers. International Journal of Performance Analysis of Sport,(13),1, 1-3.

O'Donoghue, P.G. (2010). Research methods for sports performance analysis. Routledge: London

O’Donoghue, P. (2009). Interacting Performances Theory. International Journal of Performance Analysis of Sport. (9), 26-46.

Olsen, E. \& Larsen, O. (1997). Use of match analysis by coaches. In T. Reilly, J. Bangsbo \& M. Hughes (eds), Science and Football III. 209-220. London: E\&F Spon.

Olsen, E. (1981). Football tactics. Unpublished work. In Tenga, A. (2009). Reliability and Validity of Match Performance Analysis in Soccer. PhD Dissertation for the Norwegian school of Sports Sciences. Available online at: http://brage.bibsys.no/xmlui/bitstream/handle/11250/171287/Tenga\%202009.pdf?sequence= 1

Partington, M. \& Cushion, C. (2013). An investigation of the practice activities and coaching behaviour of professional top-level youth soccer coaches. Scandinavian Journal of Medicine \& Science in Sports, 23, 372-382.

Premier League 2011/12. WhoScored.com: Revolutionising Football Statistics. 14/05/13.available on-line at: http://www.whoscored.com/Regions/252/Tournaments/2/Seasons/2935/Stages/5476/TeamS tatistics/England-Premier-League-2011-2012

Premier League 2012/13. WhoScored.com: Revolutionising Football Statistics. 14/05/13.available on-line at: http://www.whoscored.com/Regions/252/Tournaments/2/England-Premier-League

Prozone (2011). Prozone Analysis: Effective Attacking Play: Leeds, 2/11/ 2011. Available on line at: http://www.prozonesports.com/news.html

Potrac, P. \& Jones, R. (2009) Micro-political workings in semi-professional football Coaching. Sociology of Sport Journal. 26, 557577.

Pollard, R. (2002). Charles Reep (1904-2002): pioneer of notational and performance analysis in football. Journal of Sports Sciences, 20, 853-855.

Potrac, P., Jones, R. L. \& Amour, K. A. (2002) It's all about getting respect: the coaching behaviors 
Running Title: The wider context of performance analysis and it application in the football coaching process.

of an expert English soccer coach. Sport, Education and Society. 7, 183202.

Reep, C. and Benjamin, B. (1968). Skill and chance in association Football. Journal of the Royal Statistical Society, 131, 581-585.

Roxburgh, A. (2005). Jose Mourinho talks about this coaching philosophies: 11 What trends do you see at the top level of the game? League Managers Association. 30/01/2005. Available on line at: http://www.leaguemanagers.com/lmatv/interview-4882.html

Salmoni, A., Schmidt, R. \& Walter, C. (1984). In M. Hughes \& I. Franks, M (Eds.) The essentials of performance analysis an introduction. Routledge: London, 2008.

Sparkes, A. (1992). Research in Physical Education \& Sport: Exploring Alternative Vision. The Falmor Press: London.

Stanhope, J. (2001). An investigation into possession with respect to time in the Football World Cup 1994. In M. Hughes, (Ed.), Notational analysis of sport III. Cardiff: UWIC. 155162.

Strudwick, A.J. (2013). Contemporary issues in the physical preparation of elite players. In M. Williams (Ed.), Science and Football: Developing elite performers. Routledge: London, 335-372.

Taylor, J.B., Mellalieu, S.D., James, N. \& Shearer, D. (2008). The influence of match location, quality of opposition and match status on technical performance in professional association football. Journal of Sports Sciences, 26: 885-895.

Tenga, A. (2009). Reliability and Validity of Match Performance Analysis in Soccer. PhD Dissertation for the Norwegian school of Sports Sciences. Available online at: http://brage.bibsys.no/xmlui/bitstream/handle/11250/171287/Tenga\%202009.pdf?sequence $=$ 1

Tenga, A., Holme, I., Ronglan, L. T., Bahr, R. (2010). Effect of playing tactics on achieving score-box possessions in a random series of team possessions from Norwegian professional football matches. Journal of Sports Sciences, 28(3), 245-255.

Vander Linden, D., Cauraugh, J. \&Greene, T. (1993). In M. Hughes \& Franks, M (Eds.), The essentials of performance analysis an introduction. Routledge, 2008.

Vickers, J. Skill acquisition: designing optimal learning environments. In D. Collins, A. Button, H. Richards (Eds.), Performance psychology a practitioner's guide. Churchill Livingstone Elsevier, London. 2011, 140-159.

Weaver, P. (2007). One second thoughts... Egil Olsen. Talking sport: The Guardian. Available online at: http://www.theguardian.com/sport/blog/2007/apr/04/onsecondthoughtsegilolsen

Wiltshire, H. (2013). Sports performance analysis for high performance managers. In T. McGarry, P. O'Donoghue \& J. Sampaio (Eds), Routledge Handbook of Sports Performance Analysis. Routledge: Oxon, 176-187.

Winstein, C. \& Schmidt, R. (1990). In Hughes, M. \& I. Franks, M (Eds.), The essentials of performance analysis an introduction. Routledge: London, 2008.

Wooster, B. (2013). Football Analytics.The MIT Sloan Sports Analytics Conference. Boston, March 2013. Available on line at:http://www.youtube.com/watch?v=2Ye-mvV9ELI

Wright, C., Atkins, S., Polman, R., Jones, B. Sargeson, L. (2011). Goal Scoring Opportunities in Professional Football. International Journal of Performance Analysis in Sport. 11,438 449.

Wright, C; Atkins, S; Jones, B. (2012). An analysis of elite coaches' engagement with 
Running Title: The wider context of performance analysis and it application in the football coaching process.

performance analysis services (match, notational analysis and technique analysis). International Journal of Performance Analysis of Sport, (16), 436-451.

Wright, C; Atkins, S; Jones, B, Todd, J. (2013).The role of an elite match analysts within football. International Journal of Performance Analysis, 22, 240-261.

Yiannakos, A. \& Armatas, V. (2006). Evaluation of goal scoring patterns in the European Championship in Portugal 2004. International Journal of Performance Analysis in Sport, (6), 178-188. 
Running Title: The wider context of performance analysis and it application in the football coaching process.

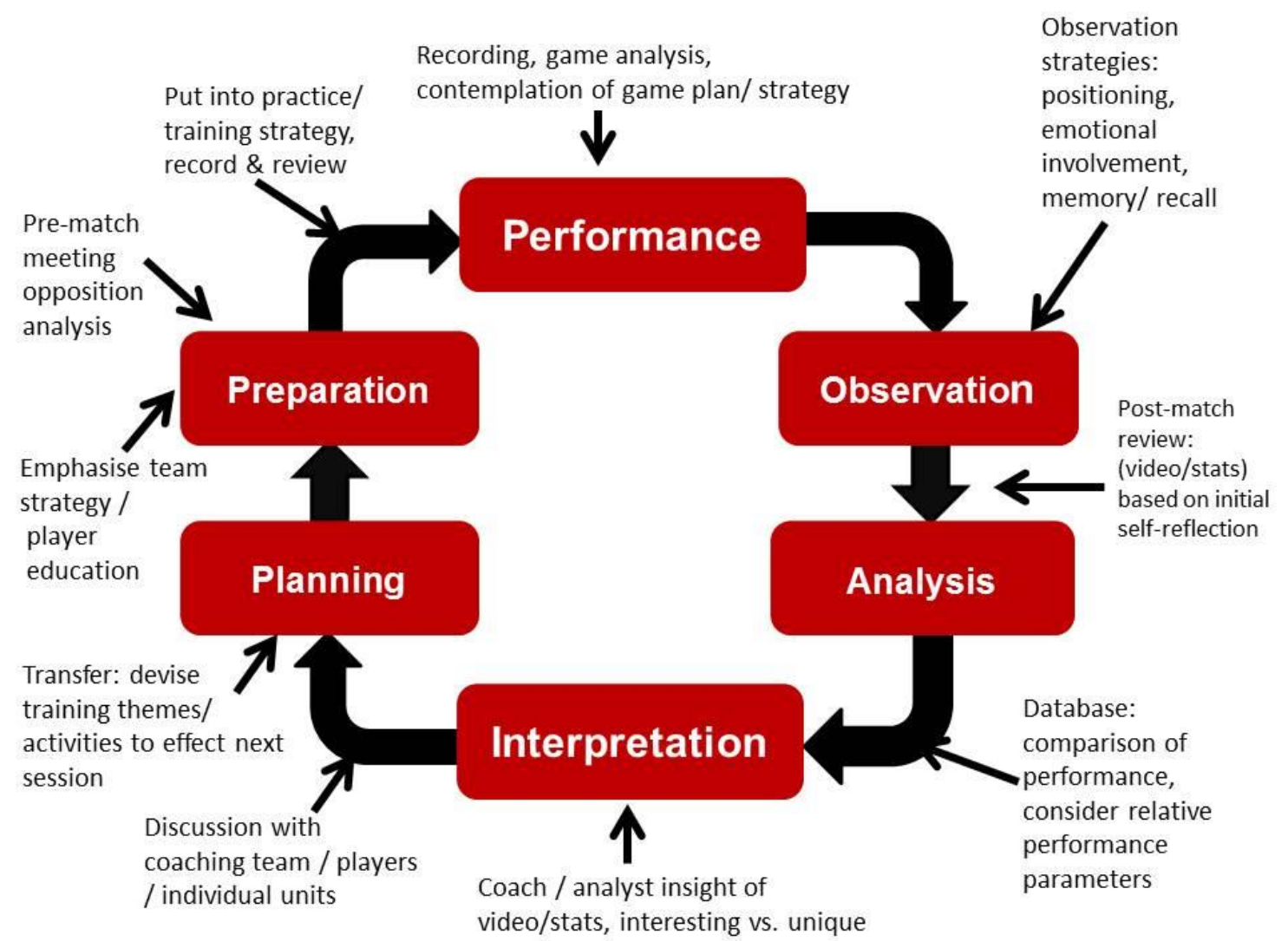

Figure1: Pre and post-match analysis within the weekly coaching cycle. Adapted from Carling 2005, and Duckett 2012. 